\title{
THE EFFECT OF TOPICAL PILOCARPINE ON PULSATILE OCULAR BLOOD FLOW
}

\author{
K. G. CLARIDGE \\ London
}

\begin{abstract}
SUMMARY
Ocular blood flow is considered an important factor in determining the extent of visual damage occurring in primary open angle glaucoma (POAG). The effect of topical pilocarpine, a parasympathomimetic vasodilator, on the pulsatile ocular blood flow (POBF) in POAG subjects was studied. A pneumotonometer linked to the Langham Ocular Blood Flow System recorded the intraocular pressure (IOP) pulse from which POBF was calculated. Measurements were taken from 18 POAG subjects treated with both $G$ pilocarpine and $G$ timolol, 2 weeks after withdrawing $G$ pilocarpine and again 1 week after reinstituting full treatment. Recordings from 20 POAG patients treated with only $\mathrm{G}$ timolol were taken as control values. There was no significant difference in the IOP or POBF between the controls and POAG patients on dual therapy. Furthermore when $\mathbf{G}$ pilocarpine was temporarily withdrawn there was no significant change in POBF despite a significant rise in IOP. The results imply that aqueous pilocarpine has no direct effect on the pulsatile component of ocular blood.
\end{abstract}

Primary open angle glaucoma (POAG) is classically associated with raised intraocular pressure (IOP), glaucomatous visual field loss and optic disc cupping. To date treatment has been aimed at reducing the IOP to within normal levels. However, despite satisfactory IOP control, some patients continue to show visual deterioration. ${ }^{1-3}$ These findings, along with the increasing recognition of normal tension glaucoma, have led many workers in this field to speculate on the importance of ocular blood flow, in particular to the optic nerve head, in the aetiology of glaucoma. ${ }^{4}$ It is not known conclusively how present treatments used in glaucoma therapy affect ocular blood flow. Several authors have found that although timolol, a commonly used non-selective topical beta blocker, is effective in reducing IOP it does not improve ocular blood flow. ${ }^{5-8}$ There is some evidence the beta-1-selective blocker, betaxolol, may increase ocular blood flow ${ }^{8}$ and that there

Correspondence to: Ms K. G. Claridge, DO, FCOphth, Department of Clinical Pharmacology, St. Thomas' Hospital, Lambeth Palace Road, London SE1 7EH, UK. is a greater preservation of visual fields in patients treated with betaxolol as opposed to timolol. ${ }^{9}$

Pilocarpine, a muscarinic parasympathomimetic, is effective in reducing IOP, but because of its side effects, namely miosis and spasm of accommodation in pre-presbyopic subjects, it has become a second line drug in the treatment of POAG in most centres. The uveal circulation is derived from the posterior ciliary circulation, as is the optic nerve head circulation. It has a dense neural innervation in which the parasympathetic system is vasodilatory. Intra-arterial injections of acetylcholine cause an increase in choroidal blood flow in rabbits and cats, ${ }^{10,11}$ and acetylcholine activity has been isolated in the ciliary nerves of primates. ${ }^{12}$ Stimulation of the facial nerve, which supplies parasympathetic fibres to the uveal tissue, causes a marked vasodilatation in the choroid in rabbits and monkeys. ${ }^{13,14}$

From this evidence pilocarpine might be expected to reduce vascular resistance and improve ocular perfusion when used in the treatment of glaucoma, and several groups have studied this effect. Animal studies, using the microsphere technique, have failed to show a significant increase in choroidal blood flow after topical pilocarpine. ${ }^{15-17}$ In healthy human subjects ocular perfusion pressures, measured by oculo-oscillo-dynamography, showed a modest increase in systolic ciliary perfusion after topical pilocarpine. ${ }^{18}$ Recent pneumotonometer studies have demonstrated a significant increase in the pulsatile component of ocular blood flow after $4 \%$ pilocarpine gel, but not after $2 \%$ aqueous drops. ${ }^{8}$

All these studies used pilocarpine in isolation. However, as mentioned, it is more usual to prescribe pilocarpine in combination with a beta blocker, when the latter is ineffective on its own and the patient is unsuitable for drainage surgery. The present report studied the effect of chronically administered pilocarpine, given in conjunction with topical timolol, on the pulsatile ocular blood flow.

\section{PATIENTS AND METHODS}

\section{Patient Selection and Entry}

Two groups of glaucoma subjects were recruited from the 
outpatient department: 18 patients treated with both topical $\mathrm{G}$ pilocarpine and $\mathrm{G}$ timolol, and 20 patients treated with $\mathrm{G}$ timolol only, these latter subjects acting as controls. All patients were diagnosed as having POAG, originally presenting with a raised IOP $(>22 \mathrm{mmHg}$ ), glaucomatous optic disc cupping and visual field loss, and an open iridocorneal angle. Some had had a laser trabeculoplasty but none had undergone intraocular surgery or had another ocular disease. They were all systemically well, no patient was diabetic and no patient was taking systemic medication that could affect ocular blood flow.

Not all patients in the pilocarpine and timolol group were on the same concentraton of $\mathrm{G}$ pilocarpine: 7 were on $4 \%, 3$ on $3 \%, 5$ on $2 \%$ and 3 on $1 \%$. All took their eyedrops four times a day. In addition all subjects were on $\mathrm{G}$ timolol $0.25 \%$ twice daily apart from 4 who were taking $G$ timolol $0.5 \%$. The average age of subjects in the pilocarpine and timolol group was 63.0 years (SD 9.2 years) and their mean refractive error was 0.09 dioptres (SD 0.50 dioptres). All control subjects were taking $G$ timolol $0.25 \%$ twice daily; their average age was 63.5 years (SD 11.7 years) and refractive error -0.52 dioptres (SD 1.04 dioptres). There were no significant differences in the ages or refractive errors between the two groups.

\section{Study Design}

Ocular blood flow was measured in the supine position after 15 minutes' rest, using a pneumotonometer probe linked to the Langham Ocular Blood Flow System. This technique measures the IOP pulse from which average IOP (diastolic IOP plus half pulse amplitude), pulse amplitude (the difference between systolic and diastolic IOP), heart rate and an estimate of pulsatile ocular blood flow (POBF) and pulse volume (POBF divided by heart rate) were derived as previously described. ${ }^{19,20}$ Systemic blood pressure was measured with a Takeda autosphygmomanometer and mean blood pressure was defined as diastolic blood pressure plus one third of the pulse pressure. All measurements were taken in at least duplicate between 0900 and 1800 hours.

Control subjects were measured on one occasion. Subjects in the pilocarpine and timolol group were measured three times: initially on both medications, 2 weeks after temporarily withdrawing $\mathrm{G}$ pilocarpine, and finally 1 week after restarting $\mathrm{G}$ pilocarpine. For any one subject serial measurements were recorded at approximately the same time of day. The study was approved by the Ethics Committee of West Lambeth Health authority and each subject gave written informed consent to participate.

\section{Statistical Analysis}

Comparisons between the timolol-only and pilocarpine and timolol groups were made by Student's unpaired $t$-test for the following parameters: IOP, pulse amplitude, pulse volume, POBF, heart rate and mean blood pressure. Student's paired $t$-test was used to compare the above parameters in the pilocarpine and timolol group whilst on and off $G$ pilocarpine. Subgroups within the pilocarpine and timolol group according to the strength of $\mathrm{G}$ pilocarpine used, were compared by analysis of variance.

\section{RESULTS}

Measurements taken from only one eye of each subject were used in the analysis. If both eyes fitted the diagnostic criteria, the eye with the most marked clinical signs was included. For the timolol and pilocarpine group there were no significant differences between the initial set of measurements and those taken after reinstituting treatment and thus, for clarity, comparisons were made using the former measurements. Table I shows the group means for the measured parameters in the timolol-only group and in the pilocarpine and in timolol group whilst on full treatment and when $\mathrm{G}$ pilocarpine was temporarily withdrawn.

\section{Comparison of Timolol-Only Group with Pilocarpine and Timolol Group on Full Treatment}

No significant differences were found in the corresponding mean values of the timolol-only group and the pilocarpine and timolol group whilst on full treatment. In particular when $G$ pilocarpine was administered in combination with $\mathrm{G}$ timolol there was no statistical difference in ocular pulse amplitude, pulse volume or POBF.

\section{Effect of Pilocarpine Treatment}

When subjects in the pilocarpine and timolol group temporarily discontinued $\mathrm{G}$ pilocarpine there was a significant rise in IOP $(P<0.03)$. This was accompanied by a small decrease in ocular pulse volume and POBF, but neither of these parameters showed a significant change. There was no accompanying change in systemic blood pressure or heart rate.

Table I. The group means for the parameters concerned with POBF in the timolol-only group and the pilocarpine and timolol group both on and off pilocarpine treatment

\begin{tabular}{|c|c|c|c|}
\hline \multirow{3}{*}{$\frac{\text { Parameter }}{\text { Heart rate (beats/min) }}$} & \multirow[b]{2}{*}{ Timolol-only } & \multicolumn{2}{|c|}{ Pilocarpine and timolol group } \\
\hline & & On pilocarpine & Off pilocarpine \\
\hline & $63.8 \quad(59.6,68.1)$ & $61.6(57.9,65.4)$ & $61.9(57.6,66.2)$ \\
\hline Mean BP (mmHg) & $98.1 \quad(91.5,104.7)$ & $107.1 \quad(98.9,115.4)$ & $104.5(95.9,113.0)$ \\
\hline IOP (mmHg) & $18.7 \quad(16.9,20.5)$ & $19.0(16.8,21.1)$ & $22.6 *(19.9,25.3)$ \\
\hline Pulse amplitude (mmHg) & $1.6(1.3,2.0)$ & $1.7(1.4,2.1)$ & $1.9(1.4,2.3)$ \\
\hline Pulse volume $(\mu \mathrm{l})$ & $4.8 \quad(3.9,5.8)$ & $5.1 \quad(4.3,5.9)$ & $4.8 \quad(3.9,5.7)$ \\
\hline $\operatorname{POBF}(\mu \mathrm{l} / \mathrm{min})$ & $315 \quad(237,395)$ & $310 \quad(264,355)$ & $(238,338)$ \\
\hline
\end{tabular}

Values are the mean with the $95 \%$ confidence limits in parentheses.

IOP, intraocular pressure; POBF, pulsatile ocular blood flow; BP, blood pressure.

${ }^{*} p<0.03$ (Student's paired $t$-test). 


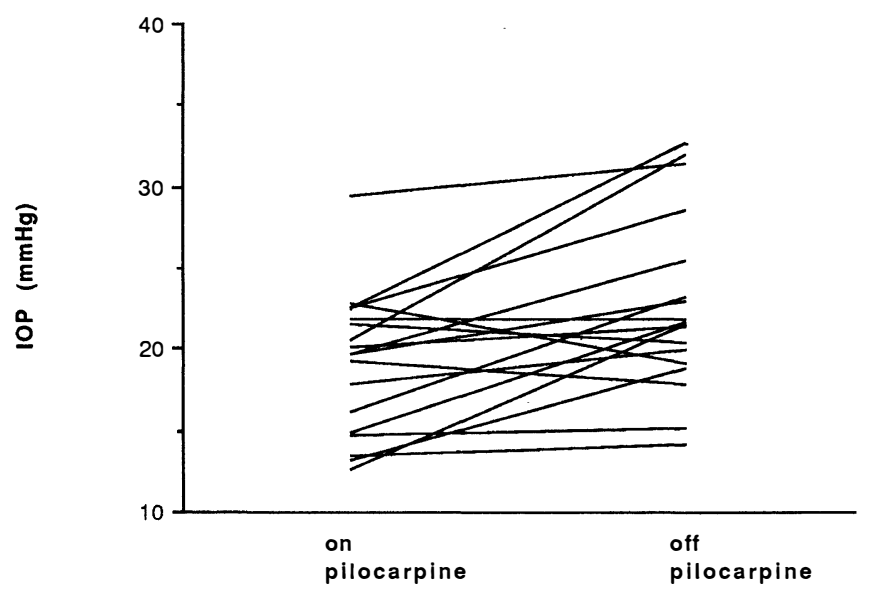

Fig. 1. Change in intraocular pressure in individual subjects when on and off pilocarpine treatment.

The concentration of $G$ pilocarpine varied between subjects but analysis of variance failed to show any significant differences in the values for the different subgroups. In particular when the subjects taking G pilocarpine $4 \%$ were analysed on their own there were no significant differences from the overall group results.

\section{Responses of Individual Patients}

Figs. 1 and 2 show the changes in IOP and POBF for the individual subjects in the pilocarpine and timolol group, when on and temporarily off $\mathrm{G}$ pilocarpine treatment. All but 4 subjects showed a rise in IOP when G pilocarpine was stopped. In contrast, although half the subjects showed a decrease in POBF when G pilocarpine was withdrawn, the rest did not. One of these subjects had a rise in POBF of $56 \%$ despite an increase in IOP. Furthermore others maintained a persistently low POBF whether on or off $\mathrm{G}$ pilocarpine. No correlation was found between the increase in IOP and accompanying change in POBF when $G$ pilocarpine was withdrawn (Kendall correlation coefficient: tau $=0.1, p>0.5$ ).

\section{DISCUSSION}

These results demonstrate that despite being an effective ocular hypotensive, $\mathrm{G}$ pilocarpine did not significantly increase the pulsatile component of ocular blood flow when given in conjunction with $\mathrm{G}$ timolol. Indeed in some cases POBF was dramatically reduced. Trew and $\mathrm{Smith}^{7}$ have shown that untreated glaucoma subjects have lower POBF values than ocular hypertensives and so it might be expected that patients on dual therapy might have more glaucomatous damage and therefore an even lower POBF than patients controlled by a beta blocker alone. By comparing the timolol-only group and the pilocarpine and timolol group when $\mathrm{G}$ pilocarpine was withdrawn, although the latter group had a slightly lower mean POBF, the difference was not significant; this indicates there was no statistical difference in the POBF in the two groups even when they were on equivalent treatment regimes, i.e. $G$ timolol only. It might be that 2 weeks was an insufficient washout period for pilocarpine. However, in the group as a whole there was a significant rise in IOP and in all subjects the pupils dilated during the withdrawal period, indicating reduced pilocarpine activity in the anterior segment at least.

The 95\% confidence intervals indicate much variation between individuals. A 22\% difference in POBF between the on and off treatment phases would be required for this study to have a $90 \%$ power of detecting a significant $(p<0.05)$ change. In fact the measured difference in POBF was $7 \%$, and the trial would have a power of only $18 \%$ to detect such a small change as being significant. These results are consistent with those of Boles Carenini et al. ${ }^{8}$ who showed that, after an 8-day washout period, 2 weeks of treatment with $\mathrm{G}$ pilocarpine $2 \%$ three times a day resulted in an insignificant $(20.6 \%)$ increase in POBF, in a series of 14 patients (26 eyes). However, these authors found in a smaller series of 6 patients (12 eyes), a significant $(54 \%)$ increase in POBF after 2 weeks of treatment with pilocarpine gel $4 \%$ daily. In order for pilocarpine to have an effect on the ocular vascular resistance it needs to reach the choroidal vessels in adequate concentrations. These results indicate that in aqueous solution pilocarpine is not absorbed in sufficient concentrations - in contrast to the slow-release gel preparation. There is some evidence that the vasodilatation seen in the choroid on stimulating the facial nerve is non-muscarinic and mediated through another transmitter, perhaps vasoactive intestinal peptide (VIP). ${ }^{14,21,22}$ This does not mean there are not other cholinergic-dependent vasodilatory mechanisms controlling ocular perfusion, but as yet their site and nature are unclear.

Some of the variation between subjects might be explained by a real difference in their ocular condition. Evidence is accumulating to suggest a heterogeneity amongst glaucoma patients, ${ }^{4}$ who might therefore respond differently to standard treatment regimes.

Before concluding, it is important to realise the limitations of using the pneumotonometer technique for assessing ocular blood flow. It measures only the pulsatile component of total ocular blood flow, and since the retinal circulation accounts for less that $5 \%$ of the ocular cir-

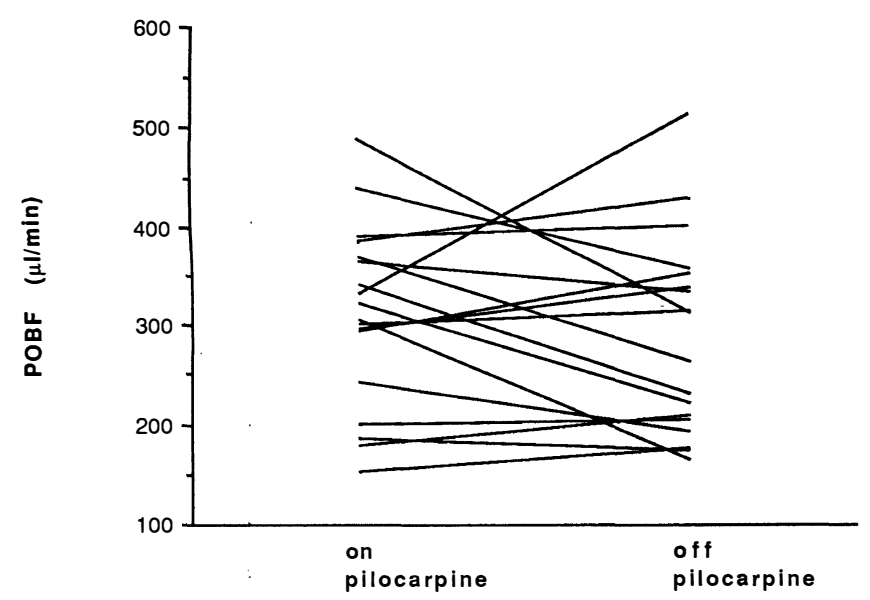

Fig. 2. Change in pulsatile ocular blood flow in individual subjects when on and off pilocarpine treatment. 
culation $^{23,24}$ it essentially measures the posterior ciliary circulation which is largely choroidal. Only a minute fraction of the posterior ciliary circulation supplies the critical optic nerve head region; this appears to be under autoregulatory control, ${ }^{25-29}$ thought to be absent in the choroid. ${ }^{21}$ However, recent laser Doppler flowmetry studies in rabbits have suggested possible myogenic autoregulation within the choroid. ${ }^{30}$ This technique does not measure changes occurring in non-pulsatile ocular blood flow, which has been demonstrated by ultrasound Doppler, ${ }^{31}$ the proportion of which may vary between individuals.

To conclude, these results indicate that aqueous pilocarpine does not increase ocular blood flow significantly and, therefore, in view of its side effects and the frequency of administration, it should remain for the present a second line drug in the treatment of POAG. Slow-release preparations appear to increase ocular perfusion, and thus may have a place in the medical management of glaucoma. Larger prospective trials on previously untreated glaucoma subjects are required to confirm these results.

I should like to thank Professor S. E. Smith for his valuable advice on preparing the protocol and manuscript, Nic Taub for advice on statistics, Karen Clarke and Ian Fisher for technical help and Jan Andrews for secretarial assistance. The work was funded by the Iris Fund for Prevention of Blindness and the Special Trustees of St Thomas' Hospital, and the Langham Ocular Blood Flow System was purchased with a generous grant provided by Dispersa (UK) Ltd.

Key words: Glaucoma, Ocular blood flow, Pilocarpine.

\section{REFERENCES}

1. Schulzer M, Mikelberg FS, Drance SM. Some observations on the relation between intraocular pressure reduction and the progression of glaucomatous visual loss. $\mathrm{Br} \mathrm{J}$ Ophthalmol 1987;71:486-8.

2. Smith RJH. The Lang Lecture 1986. The enigma of primary open-angle glaucoma. Trans Ophthalmol Soc UK 1986;105:618-33.

3. Kidd MN, O'Connor M. Progression of field loss after trabeculectomy: a five year follow-up. $\mathrm{Br} \mathrm{J}$ Ophthalmol 1985;69:827-31.

4. Schulzer M, Drance SM, Carter CJ, Brooks DE, Douglas GR, Lau W. Biostatistical evidence for two district chronic open angle glaucoma populations. $\mathrm{Br} \mathrm{J}$ Ophthalmol 1990;74:196-200.

5. Yan H, Chiou GCY. Effects of L-timolol, D-timolol, haloperidol and domperidone on rabbit retinal blood flow measured with laser doppler method. Ophthalmic Res 1987; 19:45-8.

6. Martin XD, Rabineau PA. Vasoconstrictive effect of topical timolol on human retinal arteries. Graefes Arch Clin Exp Ophthalmol 1989;227:526-30.

7. Trew DR, Smith SE. Postural studies in pulsatile ocular blood flow. II. Chronic open angle glaucoma. Br J Ophthalmol 1991;75:71-5.

8. Boles Carenini B, Brogliatti B, Boles Carenini A. Pulsatile ocular blood flow and antiglaucomatous drugs. New Trends Ophthalmol 1992;7:195-200.

9. Messmer C, Flammer J, Stümpfig D. Influence of betaxolol and timolol on the visual fields of patients with glaucoma. Am J Ophthalmol 1991;112:678-81.
10. Bill A. Autonomic nervous control of uveal blood flow. Acta Physiol Scand 1962;56:70-81.

11. Friedman E, Kopald HH, Smith TR. Retinal and choroidal blood flow determined with krypton-85 anesthetized animals. Invest Ophthalmol 1964;3:539-47.

12. Laties AM, Jacobowitz D. A comparative study of the autonomic innervation of the eye in monkey, cat, and rabbit. Anat Rec 1966;156:383-96.

13. Ruskell GL. Facial parasympathetic innervation of the choroidal blood vessels in monkeys. Exp Eye Res 1971;12:166-72.

14. Stjernschantz J, Bill A. Vasomotor effects of facial nerve stimulation: noncholinergic vasodilation in the eye. Acta Physiol Scand 1980;109:45-50.

15. Alm A, Bill A, Young FA. The effects of pilocarpine and neostigmine on the blood flow through the anterior uvea in monkeys: a study with radioactively labelled microspheres. Exp Eye Res 1973;15:31-6.

16. Chiou GCY, Yan H. Effects of antiglaucomatous drugs on the blood flow in rabbit eyes. Ophthalmic Res 1986;18: 265-9.

17. Green K, Hatchett TL. Regional ocular blood flow after chronic topical glaucomatous drug treatment. Acta Ophthalmol 1987;65:503-6.

18. Pillunat L, Stodtmeister R. Effect of different antiglaucomatous drugs on ocular perfusion pressures. J Ocular Pharm 1988;4:231-42.

19. Langham ME, Farrell RA, O'Brien V, Silver DM, Schilder P. Blood flow in the human eye. Acta Ophthalmol (Copenh) 1989;67 (Suppl 191):9-13.

20. Silver DM, Farrell RA, Langham ME, O'Brien V, Schilder P. Estimation of pulsatile ocular blood flow from intraocular pressure. Acta Ophthalmol (Copenh) 1989;67(Suppl 191): 25-9.

21. Bill A, Sperber GO. Control of retinal and choroidal blood flow. Eye 1990;4:319-25.

22. Uddman R, Alumets J, Ehinger B, Hakanson R, Loren I, Sundler F. Vasoactive intestinal peptide nerves in ocular and orbital structures of the cat. Invest Ophthalmol Vis Sci 1980;19:878-85.

23. Alm A, Bill A. Ocular and optic nerve blood flow at normal and increased intraocular pressures in monkeys (Macaca irus): a study with radioactively labelled microspheres including flow determinations in brain and some other tissues. Exp Eye Res 1973;15:15-29.

24. Riva CE, Grunwald JE, Sinclair SH, Petrig BL. Blood velocity and volumetric flow rate in human retinal vessels. Invest Ophthalmol Vis Sci 1985;26:1124-32.

25. Ernest T. Autoregulation of blood flow in the distal segment of the optic nerve. In: Krieglstein GK, Leydhecker W, editors. Glaucoma update. Berlin: Springer, 1979:93-100.

26. Geijer C, Bill A. Effects of raised intraocular pressure on retinal, prelaminar, laminar and retrolaminar optic nerve blood flow in monkeys. Invest Ophthalmol Vis Sci 1979;18: $1030-42$.

27. Riva CE, Grunwald JE, Sinclair SH. Laser doppler measurements of relative blood velocity in the human optic nerve head. Invest Ophthalmol Vis Sci 1982;22:241-8.

28. Sossi N, Anderson DR. Effect of elevated intraocular pressure on blood flow. Arch Ophthalmol 1983;101:98-101.

29. Sperber GO, Bill A. Blood flow and glucose consumption in the optic nerve, retina and brain: effects of high intraocular pressure. Exp Eye Res 1985;41:639-53.

30. Kiel JW, Shepherd AP. Autoregulation of choroidal blood flow in the rabbit. Invest Ophthalmol Vis Sci 1992;33:2399-410.

31. Canning CR, Restori M. Doppler ultrasound studies of the ophthalmic artery. Eye 1988;2:92-5. 